\title{
Myo-inositol transport into endothelial cells derived from nervous system microvessels
}

\author{
Peter E. Kollros ${ }^{1,2}$, Gary W. Goldstein ${ }^{1,2, *}$ and A. Lorris Betz ${ }^{1-3}$ \\ University of Michigan Medical Center, Departments of 'Pediatrics, ${ }^{2}$ Neurology and ${ }^{3}$ Surgery, Ann Arbor, MI (U.S.A.)
}

(Accepted 8 August 1989)

Key words: Blood-retinal barrier; Blood-brain barrier; Vitreous humor; Brain interstitial fluid; Diabetic retinopathy

\begin{abstract}
Myo-inositol, the precursor in the biosynthesis of inositol phospholipids and inositol phosphates, is found in many tissues at concentrations well above its concentration in the plasma, but the highest concentrations are found in the central nervous system and the neuroretina. We describe an active, sodium gradient-dependent transport of myo-inositol into cultured endothelial cells derived from bovine retinal microvessels. Transport is inhibited by cytochalasin B, and phloridzin $>$ phloretin. Mannitol, sorbitol, and fructose do not inhibit uptake, but D-galactose inhibits uptake $>$ L-glucose $>$ D-glucose. The apparent $K_{\mathrm{m}}$ of this transport system is $311 \pm 47$ (S.D.) $\mu \mathrm{M}$ and the apparent $V_{\max }$ is $40.8 \pm$ 2.8 (S.D.) pmol $\cdot \mathrm{mg}$ protein ${ }^{-1} \cdot \mathrm{min}^{-1}$. This transport system may be a key in the maintenance of high tissue concentrations as it could concentrate myo-inositol from the plasma into the extracellular spaces of the eye and central nervous system.
\end{abstract}

\section{INTRODUCTION}

Myo-inositol is an important precursor to the biosynthesis of inositol phospholipids and inositol phosphates, compounds which play an important role in signal transduction ${ }^{3,19}$. In mammals, myo-inositol is present in plasma at concentrations ranging from 25 to $100 \mu \mathrm{M}^{12 \text {, }}$ 14,17. Intracellular concentrations of myo-inositol are several-fold higher than in the circulation, with brain and neuroretinal tissue having the highest concentrations ${ }^{2}$, 17,18,21. Although high intracellular concentrations could be maintained either by active myo-inositol transport or by synthesis from glucose, transport appears to be the primary mechanism for two reasons. First, the activity of the rate limiting enzyme in the synthesis of myo-inositol, inositol 1-phosphate synthetase (EC.5.5.1.4), is low in most tissues ${ }^{28}$. Second, elevated plasma glucose concentrations are associated with lowered rather than elevated myo-inositol tissue concentrations ${ }^{8,10,13,15,18}$.

Cerebrospinal fluid (CSF) and ocular vitreous humor concentrations of myo-inositol are also higher than plasma levels ${ }^{17,18,23}$. Transport of this compound from blood to brain in vivo and by the isolated choroid plexus in vitro has been reported ${ }^{24}$. However, active transport systems capable of maintaining myo-inositol concentration gradients between plasma and CSF or vitreous humor have not been previously described in endothelial cells that form the blood-brain and blood-retinal barriers. In this report, we characterize the transport of myo-inositol into cultured endothelial cells derived from bovine retinal microvessels. Retinal microvessels display similar structural and functional properties to brain microvessels, and endothelial cells in each form bloodtissue barriers. We show here that myo-inositol is transported by an active transport process dependent on the transmembrane sodium gradient and inhibited by glucose galactose, phloridzin, phloretin and cytochalasin B.

\section{MATERIALS AND METHODS}

\section{Cell acquisition and culture}

Retinal endothelial cells were obtained by a modification of methods previously described ${ }^{6}$. Bovine eyes were obtained from the slaughterhouse. Retinas were dissected, placed in ice-cold M-199 medium supplemented with penicillin and streptomycin, and rinsed 3 times. The retinas were strained on a $118 \mu \mathrm{m}$ nylon mesh and extensively washed. The trapped tissue was washed and then homogenized in a glass tube with a loose fitting Teflon pestle $(0.25$ $\mathrm{mm}$ clearance) at $400 \mathrm{rpm}$ for $20 \mathrm{up}$ and down strokes. The homogenate was centrifuged for $5 \mathrm{~min}$ at $1000 \mathrm{~g}$. The pellet was resuspended in M-199 and the capillaries collected on $53 \mu \mathrm{m}$ nylon mesh. The capillaries were washed into a centrifuge tube and centrifuged at $200 \mathrm{~g}$ for $2 \mathrm{~min}$. The pellet was resuspended in $0.25 \%$ collagenase/dispase and $0.5 \%$ bovine serum albumin in M-199 and gently agitated for 45-60 min. The digest was then layered over 5 $\mathrm{ml}$ of Ficol-Paque and centrifuged at $1250 \mathrm{~g}$ for $20 \mathrm{~min}$. The interface cells and the pellet were transferred to a $T_{25}$ flask coated with gelatin and incubated with minimal essential medium with L-valine replaced by $\mathrm{D}$-valine (MEM-D-Val) for 16-24 $\mathrm{h}$. The second

\footnotetext{
* Current address: Kennedy Institute, 707 N. Broadway, Baltimore, MD 21205, U.S.A.

Correspondence: P.R. Kollros. Present address: Thomas Jefferson University, Department of Pediatrics, 1025 Walnut Street, Philadelphia, PA 19107, U.S.A.
} 
day the medium was changed to MEM-D-Val supplemented with 16 $\mathrm{U} / \mathrm{ml}$ heparin and $50 \mu \mathrm{g} / \mathrm{ml}$ of endothelial growth supplement (ECGS). The cells were grown and passaged at confluency with splits of 1 to 4 . Cells used in these experiments were in the 6th through 14th passage, tested positive for low density lipoprotein (LDL) uptake and displayed the typical endothelial cell morphology on phase contrast microscopy $y^{25,26}$.

\section{Transport experiments}

Cells were grown to confluency in 24-well $(1.6 \mathrm{~cm}$ diameter) culture plates coated with fibronectin. The cells were then washed and preincubated for $12 \mathrm{~min}$ in either an inositol-free HEPES buffered Dulbecco's medium, a HEPES buffered Earle's balanced salt solution (EBS), or sodium-free EBS with choline replacing sodium. The appropriate additives except for the radioactive tracers were included in the preincubation solutions. In the cases where ouabain or 2,4-dinitrophenol (2,4-DNP) and iodoacetic acid were used, the preincubation period was extended to $30 \mathrm{~min}$. The preincubation solution was aspirated off the cells and the incubation solution was added. At the end of the incubation, the experiment was stopped by the addition of $2 \mathrm{ml}$ of ice-cold phosphate-buffered saline (PBS), pH 7.4. The cells were then quickly washed 4 more times over $20 \mathrm{~s}$ with ice-cold PBS. After the final wash, $1 \mathrm{~N} \mathrm{NaOH}$ was added to each well. The cells were dissolved overnight at room temperature and then aliquots were taken for liquid scintillation counting and for total protein determination. When quantitation of lipid and inositol was undertaken, methanol was added to each well immediately following the final PBS wash.

During the incubation, the medium or buffer solutions contained $\left[{ }^{3} \mathrm{H}\right]$ myo-inositol to measure the transport of myo-inositol and $\left[{ }^{14} \mathrm{C}\right]$ sucrose as a marker of the extracellular space. By measuring the ${ }^{14} \mathrm{C}$ disintegrations per minute (DPMs) in each sample, the contribution to the total ${ }^{3} \mathrm{H}$ DPMs from extracellular ${ }^{3} \mathrm{H}$ was determined and the intracellular label was calculated by subtracting the extracellular DPMs of ${ }^{3} \mathrm{H}$ from the total ${ }^{3} \mathrm{H}$ DPMs.

\section{Biochemical characterization of incorporated label}

We employed a modification of the method of Berridge to characterize the products of inositol incorporation ${ }^{3}$. Immediately following the final wash, methanol was added to the cell layer, which was then scraped and both the cell layer and supernatant were transferred to a glass tube. The well was washed with methanol and the wash was combined with the sample to make a total methanol volume of $1 \mathrm{ml}$. To this, $0.8 \mathrm{ml}$ of chloroform- $\mathrm{HCl}(200: 1)$ was added, followed by $2 \mathrm{ml}$ of $0.5 \mathrm{mM}$ myo-inositol dissolved in water. The sample was then vortexed and centrifuged at $5 \mathrm{~g}$ for $5 \mathrm{~min}$. The aqueous layer was separated and an aliquot of the organic layer was counted as an indication of myo-inositol incorporation into lipid. To the aqueous layer, $0.5 \mathrm{ml}$ of a $50 \%$ slurry of Dowex AGI-X8 was added and mixed with the sample for $5 \mathrm{~min}$. The sample was allowed to settle and the supernatant separated. The resin pellet was then washed twice with $5 \mathrm{mM}$ myo-inositol solution. The supernatants and aqueous layer were pooled, frozen and lyophilized. The resin was counted using a liquid scintillation counter to quantitate myo-inositol incorporation into inositol phosphates. The lyophilate was resuspended in $1 \mathrm{ml}$ of water and an aliquot counted to determine the amount of free myo-inositol. To assure the purity of the free myo-inositol, representative samples were then run through a desalting column of $1.5 \times 0.6 \mathrm{~cm}$ consisting of Dowex 1-X8 (acetate form) and $1.5 \mathrm{~cm} \times 0.6 \mathrm{~cm}$ amberlite $\mathrm{CG}-50\left({ }^{+} \mathrm{H}\right.$ form) with the Dowex placed above the Amberlite. The sample was eluted with an excess of deionized distilled water. Recovery of label from the column was $100 \%$. The effluent was frozen, lyophilized, and reconstituted in a small volume for paper chromatography. The sample and standards were run in two solvent systems, $n$-butanol: ethanol:water $(2: 2: 1)$ and $n$-butanol:pyridine:water $(6: 4: 3)$ on Whatman 1 paper. In both systems the sample co-migrated as a single peak with the $\left[{ }^{3} \mathrm{H}\right] \mathrm{myo}$-inositol standard

\section{Protein determination}

Aliquots of samples solubilized in $1 \mathrm{~N} \mathrm{NaOH}$ were neutralized with a slight excess $1 \mathrm{~N}$ acetic acid. Samples were then adjusted to an appropriate volume and Coomassie brilliant blue G-250 dye solution was added. Absorbance was read at $595 \mathrm{~nm}$ and compared to a standard scale by the method of Bradford ${ }^{7}$. Bovine gamma globulin was used as a protein standard.

\section{Water space determination}

The intracellular water space of the cultured cells was measured using 3-O-methyl-glucose $\mathrm{e}^{16}$. In this experiment, $\left[{ }^{3} \mathrm{H}\right] 3-\mathrm{O}$-methylglucose was added to the cells and incubated for $45 \mathrm{~min}$ along with $\left[{ }^{14} \mathrm{C}\right]$ sucrose as a marker of extracellular water space. Since 3-O-methyl-glucose equilibrates with the cell water during this period of time, the intracellular water space was calculated as the difference between the 3-O-methyl-glucose space and the sucrose space. The water space value was determined to be $7.4 \pm 1.2$ (S.D.) $\mu \mathrm{l} / \mathrm{mg}$ of protein $(n=4)$.

\section{Data analysis and statistics}

The Bonferroni modification of the $t$-statistic was used to make inferences based on the differences between the means of control and experimental groups ${ }^{27}$. For Table II, a logarithmic transformation of the data was done prior to applying the modified $t$-test because the sample variance appeared to be proportional to the mean values ${ }^{27}$.

Curve fitting for non-linear regressions (Fig. 4) was done by the method of least squares (SYSTAT, Systat, Evanston, IL). Our model equation was $V=\left(V_{\max }{ }^{*}[S]\right) /\left(K_{\mathrm{m}}+[S]\right)$. We also attempted to fit our data to a dual transport model but were not able to get a better fit both when no suggested solutions, and when suggested solutions from the literature were supplied. Linear regression of the sodium independent transport was also performed by the method of least squares (Fig. 4).

\section{Materials}

Cell culture medium, fetal calf serum, calf serum, penicillin, and streptomycin were purchased from GIBCO Laboratories, Grand Island, NY. ECGS was purchased from Collaborative Research, Lexington, MA. $\left[{ }^{3} \mathrm{H}\right]$ myo-inositol and $\left[{ }^{14} \mathrm{C}\right]$ sucrose were obtained from American Radiolabeled Chemicals, St. Louis, MO. $\left[{ }^{3} \mathrm{H}\right] 3-$ O-methyl-glucose was obtained from New England Nuclear, Boston, MA. Bovine immunoglobulin and Coomassie brilliant blue were acquired from Bio-Rad, Richmond, CA. Acetylated low density lipoprotein labeled with $1,1^{\prime}$-dioctadecyl-1-1-3,3,3',3'-tetramethyl-indo-carbocyanine perchlorate was acquired from Biomedical Technologies, Stoughton, MA. All other chemicals were purchased from Sigma, St. Louis, MO. Tissue culture plates and flasks were obtained from Costar, Cambridge, MA

\section{RESULTS}

\section{Temperature dependence of inositol transport and accu- mulation}

Fig. 1 shows the time course over $80 \mathrm{~min}$ for uptake of myo-inositol by cultured endothelial cells derived from retinal microvessels. The data are expressed as a ratio of the cellular concentration to the culture medium concentration of ${ }^{3} \mathrm{H}$, calculated using the measured value of 7.4 $\mu \mathrm{l} / \mathrm{mg}$ protein for the intracellular water space. Over this time course the uptake is linear and temperature dependent. Values greater than one show that there is accumulation of label from the medium into the cells so the intracellular concentration is greater than the medium concentration. This accumulation could be the result of either the active transport of myo-inositol or the metab- 


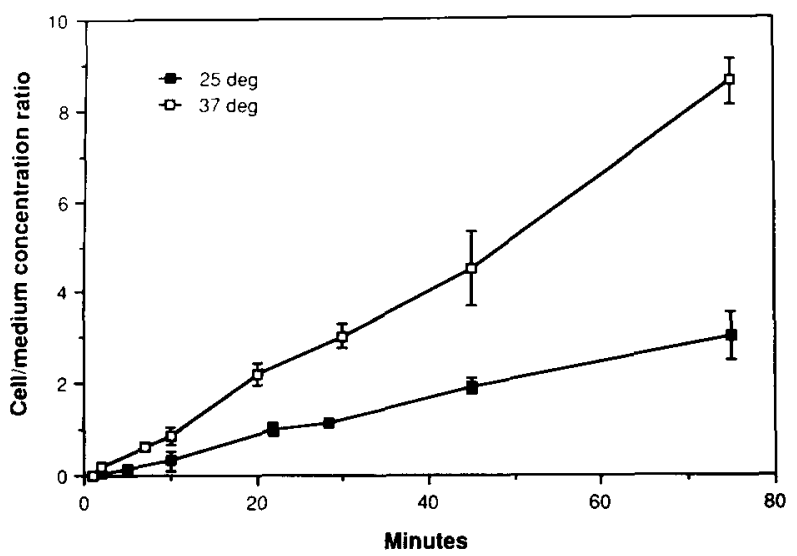

Fig. 1. Time course of myo-inositol uptake and incorporation into cultured retinal endothelial cells. Each point represents the mean of 5 replicates and the error bars are S.D. The data are presented as a concentration ratio of the intracellular concentration to the extracellular concentration. The extracellular ambient myo-inositol concentration was $6 \mu \mathrm{M}$ and water space of cells measured $7.4 \mu \mathrm{l} / \mathrm{mg}$ protein.

olism of myo-inositol to other compounds which would account for the accumulation of label, but not cause an increase in the intracellular free myo-insositol concentration.

\section{Metabolism of inositol}

Cellular uptake of myo-inositol and incorporation of myo-inositol into lipid and inositol phosphates over $21.5 \mathrm{~h}$ is shown in Fig. 2. The accumulation of labeled myo-inositol remains linear for the entire period. At early time points, virtually all of the accumulated label is in the free myo-inositol fraction. With time, an increasing amount of label is incorporated into lipid and then into inositol phosphates. To assess the purity of the myoinositol fraction, samples were desalted and subjected to paper chromatography in 2 solvent systems. ${ }^{3} \mathrm{H}$ from the

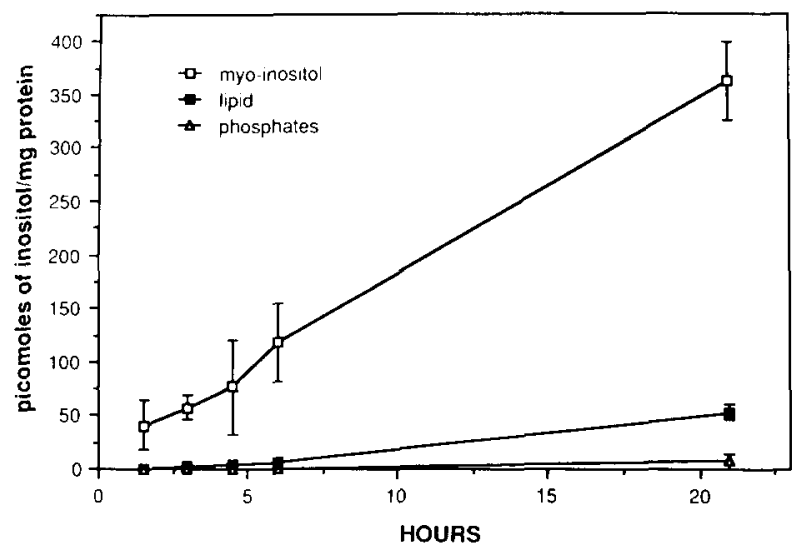

Fig. 2. Uptake and incorporation of myo-inositol into intracellular myo-inositol, inositol phospholipids, and inositol phosphates. Each value represents the mean of 4 replicates with error bars showing the S.D. The ambient myo-inositol concentration was $0.76 \mu \mathrm{M}$.

\section{TABLE I}

Effect of sodium replacement, ouabain, and energy metabolism inhibitors on myo-inositol transport

Incubations were conducted in EBS with the appropriate additives, and in sodium-free EBS (choline buffer). Sodium chloride and choline chloride were present at $150 \mathrm{mM}$. Ouabain was present at 0.1 $\mathrm{mM}, 2,4-\mathrm{DNP}$ at $0.1 \mathrm{mM}$ and iodoacetic acid at $5 \mathrm{mM}$. The extracellular myo-inositol concentration was $0.15 \mu \mathrm{M}$. Values are the mean of 6 replicates \pm S.D.

\begin{tabular}{ll}
\hline Condition & $\mathrm{fmol} \cdot \mathrm{mg} \mathrm{protein}-1 \cdot \mathrm{min}^{-1}$ \\
\hline Control buffer & $67.7 \pm 1.4$ \\
Choline buffer & $14.0 \pm 1.0^{* *}$ \\
Ouabain & $32.6 \pm 2.1^{* *}$ \\
2,4-DNP + iodoacetic acid & $34.9 \pm 1.4^{* *}$ \\
\hline
\end{tabular}

${ }^{* *} P<0.005$ compared to $150 \mathrm{mM} \mathrm{Na}^{+}$.

myo-inositol fraction co-migrated as a single peak with the myo-inositol standard. Taken together, these experiments demonstrate that metabolism does not account for the accumulation of intracellular myo-inositol. Therefore, myo-inositol is actively transported into these cells. In order to minimize the effect of metabolism of $\left[{ }^{3} \mathrm{H}\right]$ myo-inositol during long incubations, the remainder of the experiments were confined to $150 \mathrm{~min}$ or less.

Sodium gradient dependence of myo-inositol transport

Active transport in mammalian cells is accomplished either by directly using high-energy phosphorylated compounds or by deriving energy from the sodium gradient across the cell membrane through co-transport. Table I shows the results from an experiment measuring myo-inositol uptake in the presence of ouabain, 2,4-DNP and iodoacetic acid, or in sodium-free EBS. The greatest inhibition of transport occurred in the sodium-free EBS. Inhibition of $\mathrm{Na}^{+}, \mathrm{K}^{+}$-ATPase with ouabain, or disrup-

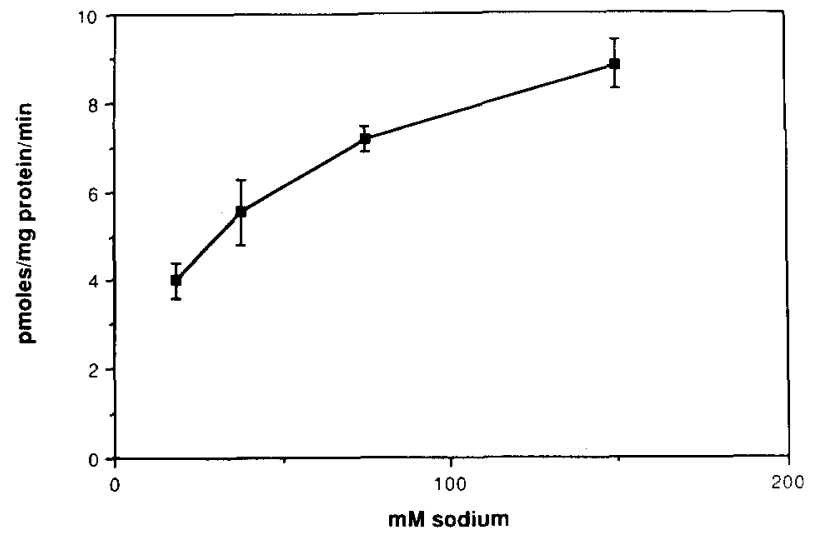

Fig. 3. Effect of sodium concentration on myo-inositol transport. Each sample represents the mean of 6 replicates with the error bars representing S.D. The ambient extracellular myo-inositol concentration was $2.4 \mu \mathrm{M}$. 


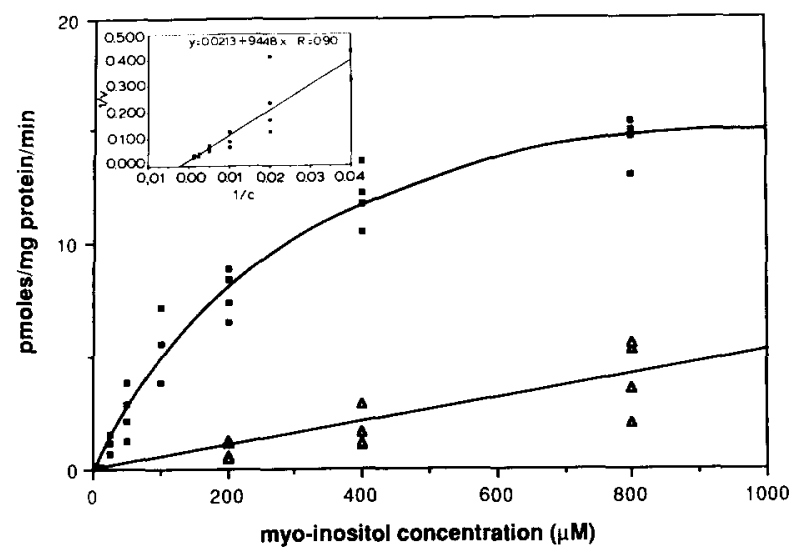

Fig. 4. Kinetics of myo-inositol transport into cultured retinal endothelial cells. The solid squares represent the sodium-dependent myo-inositol transport. These values were calculated by subtracting the measured sodium-independent transport (open triangles) from the total myo-inositol transport (not shown). The inset shows the portion of the Lineweaver-Burk transformation for data points closest to the $Y$-axis. No weighting of points was performed.

tion of energy metabolism with 2,4-DNP and iodoacetic acid, also reduced myo-inositol transport, although not to as great an extent as did sodium replacement. Fig. 3 shows the velocity of inositol transport as a function of the extracellular sodium concentration. The velocity of myo-inositol transport increases with increasing extracellular sodium, suggesting that the rate of transport is dependent upon the sodium gradient.

\section{Kinetic parameters of inositol transport}

The initial velocity of myo-inositol transport as a function of culture medium myo-inositol concentration is

\section{TABLE II}

\section{Effects of various inhibitors on myo-inositol transport}

Values are the means of 4 replicates \pm S.D.

\begin{tabular}{|c|c|c|}
\hline Compound & $\begin{array}{l}\text { Concentration } \\
(m M)\end{array}$ & $\begin{array}{l}\text { pmol } \cdot \mathrm{mg} \\
\text { protein }^{-1} \cdot \min ^{-1}\end{array}$ \\
\hline Control medium & - & $3.50 \pm 0.81$ \\
\hline \multicolumn{3}{|l|}{ Hexitols } \\
\hline Myo-inositol & 20 & $0.66 \pm 0.09^{* *}$ \\
\hline Mannitol & 20 & $2.84 \pm 0.21$ \\
\hline Sorbitol & 20 & $3.36 \pm 0.68$ \\
\hline \multicolumn{3}{|l|}{ Hexoses } \\
\hline Fructose & 20 & $2.79 \pm 0.06$ \\
\hline D-Glucose & 20 & $2.10 \pm 0.22^{*}$ \\
\hline L-Glucose & 20 & $1.72 \pm 0.45^{* *}$ \\
\hline D-Galactose & 20 & $1.52 \pm 0.41^{* *}$ \\
\hline \multicolumn{3}{|c|}{ Glucose transport inhibitors } \\
\hline Phloretin & 0.2 & $1.90 \pm 0.39^{*}$ \\
\hline Phloridzin & 0.2 & $0.65 \pm 0.15^{* *}$ \\
\hline Cytochalasin B & 0.02 & $1.65 \pm 0.35^{* *}$ \\
\hline
\end{tabular}

${ }^{*} P<0.05,{ }^{*} P<0.005$, compared to the control medium with a glucose concentration of $5.0 \mathrm{mM}$ and an ambient myo-inositol concentration of $1.35 \mu \mathrm{M}$.

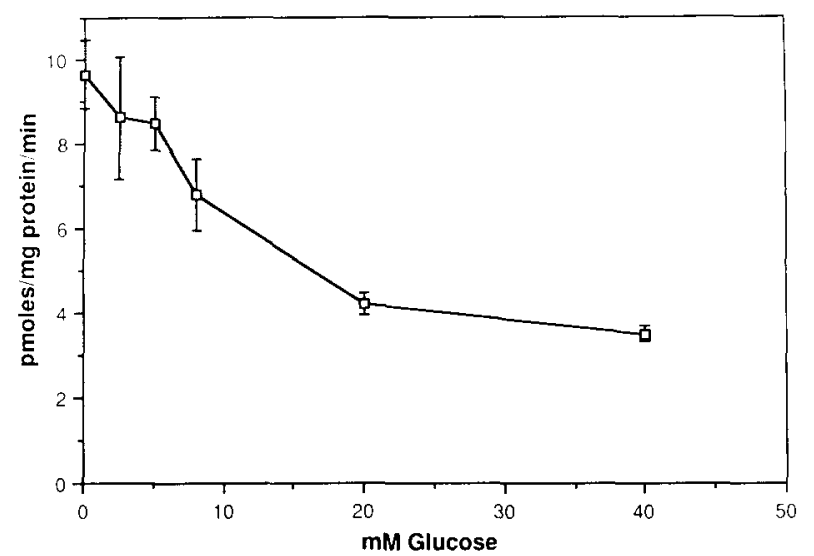

Fig. 5. Effect of glucose on the transport of myo-inositol. The open squares show the amount of myo-inositol transported at various glucose concentrations ranging between 0.5 and $40 \mathrm{mM}$. The myo-inositol concentration was $40 \mu \mathrm{M}$.

shown in Fig. 4. The portion of the transport which is sodium independent (as measured in a sodium-free choline buffer) is much less than the portion which is sodium dependent. The apparent $K_{\mathrm{m}}$ for the sodiumdependent uptake was $311 \pm 47$ (S.D.) $\mu \mathrm{M}$ and the $V_{\max }$ was $40.8 \pm 2.8$ (S.D.) $\mathrm{pmol} \cdot \mathrm{mg}$ protein ${ }^{-1} \cdot \mathrm{min}^{-1}$.

\section{Specificity of the inositol transport system}

Inositol uptake was finally characterized by measuring transport in the presence of various hexoses, hexitols, and inhibitors of the glucose transport system. The results are shown in Table II. Cold myo-inositol is a very potent inhibitor of radioactive myo-inositol transport, but the other two tested hexitols, mannitol and sorbitol, did not significantly inhibit myo-inositol transport. Fructose did not inhibit transport, but D-galactose, D-glucose and L-glucose all significantly inhibited myo-inositol transport. Finally, phloretin, phloridzin, and cytochalasin B inhibited myo-inositol transport, but the order of potency is different than that for the inhibition of glucose transport, with phloridzin being a more potent inhibitor of myo-inositol transport than phloretin ${ }^{4}$.

Fig. 5 shows the increasing inhibition of myo-inositol transport with increasing concentrations of glucose. It is important to note that even at physiologic glucose and myo-inositol concentrations, the transport of myo-inositol is inhibited to a measurable extent.

\section{DISCUSSION}

Endothelial cells derived from retinal microvessels were chosen for this study because they form the blood-tissue barrier at the retinal capillary and prevent many molecules found in the plasma from entering the retina. The function and structure of the blood-retinal barrier is very similar to the that of the blood-brain 
barrier ${ }^{5}$. In addition to excluding certain molecules from the eye and brain, these barriers also tend to buffer tissues from swings in plasma concentrations of other molecules, such as amino acids and glucose. Specialized transport systems exist at blood-tissue barriers to permit certain molecules to pass from the circulation into tissues. The major transport system for myo-inositol uptake into cultured bovine retinal microvessel endothelial cells is a saturable, carrier-mediated, active process deriving its energy from the sodium gradient. Myo-inositol is concentrated in these cells to levels well above the concentrations present in the cell culture medium. The apparent $K_{\mathrm{m}}$ of $311 \pm 47$ (S.D.) $\mu \mathrm{M}$, found in vitro suggests that the rate of transport of myo-inositol across the barrier in vivo is dependent upon the plasma myo-inositol concentration. Uptake is inhibited by replacement of sodium with choline or by addition of ouabain; both observations indicate sodium-dependent transport. Finally, uptake is inhibited by cytochalasin B, phloretin, phloridzin, Dglucose, L-glucose, galactose, but not by fructose, mannitol or sorbitol added to the cell culture medium. The order of potency of the transport inhibitors, the sodiumdependence, and the inhibition by L-glucose permit us to conclude that myo-inositol is not transported by means of the major glucose facilitated-diffusion transport system ${ }^{4}$. Even under physiologic concentrations of glucose and myo-inositol, there is measurable inhibition of transport by glucose. Since our kinetic analysis was performed in the presence of $5 \mathrm{mM}$ D-glucose, the calculated Michaelis-Menten constant represents an apparent $K_{\mathrm{m}}$.

The transport of myo-inositol into neural cells in culture has also been studied. Cultured rat Schwann cells have a saturable sodium-dependent transport system ${ }^{20}$. As in endothelial cells, transport is inhibited by glucose, galactose, phloridzin and phloretin. In this system, the $K_{\mathrm{m}}$ was $30 \mu \mathrm{M}$. In mouse neuroblastoma cells grown in culture, Yorek et al. ${ }^{29}$ found two saturable sodiumdependent transport systems, a high-affinity transport system with a $K_{\mathrm{m}}$ value of $12.4 \mu \mathrm{M}$ and a $V_{\max }$ of 14.1 pmol $\cdot \mathrm{mg}$ protein ${ }^{-1} \cdot \mathrm{min}^{-1}$ and a low-affinity system with a $K_{\mathrm{m}}$ of $433 \mu \mathrm{M}$ and a $V_{\max }$ of $215 \mathrm{pmol} \cdot \mathrm{mg}$ protein $^{-1} \cdot \min ^{-1}$. Myo-inositol transport into neuroblastoma cells was inhibited by glucose and by sorbitol ${ }^{30}$. In doing these inhibitor studies, the cells were preincubated with inhibitor for two weeks in the presence of sorbitol and in $30 \mathrm{mM}$ glucose. The inhibition by $30 \mathrm{mM}$ glucose had both competitive and non-competitive components, with the non-competitive inhibition being greater. The long preincubation time may account for the differeces in the nature of the glucose and sorbitol inhibition these authors observed compared to other investigators.

In the central nervous system, the tissue concentrations of myo-inositol are tightly controlled ${ }^{1,11}$. Normal cerebral and cerebellar myo-inositol concentrations are maintained even in the presence of dietary restriction ${ }^{1}$. Spector described a 3 tier system of myo-inositol homeostasis in brain ${ }^{22}$. The first level is regulated by renal excretion and intestinal absorption. The second level is transported into the central nervous system by the choroid plexus. The third level is by carrier-mediated transport from interstitial fluid into brain cells.

The active transport of myo-inositol by retinal microvessel endothelial cells at the blood-retinal barrier may be fundamental to its high concentration in the retina. The retinal capillary is similar to the structure of the cerebral capillary in terms of tight junctions and specialized transport systems which protect neural tissue from fluctuations in the concentrations of plasma components ${ }^{5}$. Both the brain and the retina have tissue myo-inositol concentrations that are much higher than plasma. Concentrations of myo-inositol in the vitreous humor and the CSF probably approximate the concentrations in retinal and brain interstitial fluid because there are no barriers to diffusion between these fluid spaces for small polar molecules ${ }^{5,9}$. These fluids have a myo-inositol concentration greater than the plasma but less than the concentrations in the adjacent tissues ${ }^{17,18}$. Since myoinositol is concentrated from the plasma into the extracellular fluid of the eye and brain, we presume that the transport system we describe into cultured retinal endothelial cells in vivo is located on the luminal border of the capillaries. Also implicit in this model is a mechanism for release of myo-inositol at the anti-luminal border which allows myo-inositol to flow out of the cell into the interstitial fluid. For the brain, myo-inositol transport may occur both at the capillary endothelium into interstitial fluid, and at the choroid plexus into spinal fluid. For the eye, myo-inositol transport would occur at the capillary endothelial cell into the retinal interstitial fluid. The source of myo-inositol in the vitreous humor is not known, but transport by the ciliary body into the aqueous humor with subsequent diffusion into the vitreous, and transport by the pigmented retinal epithelium may supplement diffusion into the vitreous from retinal interstitial fluid. Retinal and cerebral parenchymal cells further concentrate interstitial myo-inositol. In effect, there is a serial concentration of myo-inositol, first across the blood-tissue barrier, and second into the parenchymal cells of the retina and the brain. Coupling the myo-inositol pumps in series may explain how these two tissues maintain high concentrations of myo-inositol.

Acknowledgements. These studies were supported by the National Institutes of Health through research Grant EY03772 and NS07222. In part this work was done during the tenure of a Clinician-Scientist Award from the American Heart Association (P.R.K.). The authors are grateful to Diane Ar and Mitchell Smith for their technical assistance. 


\section{REFERENCES}

1 Allison, J.H., Boshans, R.L., Hallcher, L.M., Packman, P.M. and Sherman, W.R., The effects of lithium on myo-inositol levels in layers of frontal cerebral cortex, in cerebellum and in corpus callosum of the rat, $J$. Neurochem., 34 (1980) 456-458.

2 Berridge, M.J., Rapid accumulation of inositol trisphosphate reveals agonist hydrolyse to polyphoinositides instead of phosphatidylinositol, Biochem. J., 212 (1983) 849-858.

3 Berridge, M.J. and Irvine, R.I., Inositol trisphosphate, a novel second messenger in cellular signal transduction, Nature (Lond.), 312 (1984) 315-321.

4 Betz, A.L., Bowman, P.D. and Goldstein, G.W., Hexose transport in microvascular endothelial cells cultured from bovine retina, Exp. Eye Res., 36 (1983) 269-277.

5 Bito, L.Z. and De Rousseau, C.J., Transport functions of the blood-retinal barrier system and the micro-environment of the retina. In J.G. Chuha-Vaz (Ed.), The Blood Retinal Barriers, Plenum Press, New York, 1980, pp. 133-163

6 Bowman, P.D., Betz, A.L. and Goldstein, G.W., Primary culture of microvascular endothelial cells from bovine retina, In Vitro, 18 (1982) 626-632.

7 Bradford, M.M., A rapid and sensitive method for the quantitation of microgram quantities of protein utilizing the principle of protein dye binding, Anal. Biochem., 72 (1976) 248-254.

8 Caspary, W.F. and Crane, R.K., Active transport of myoinositol and its relation to the sugar transport system in hamster small intestine, Biochim. Biophys. Acta, 203 (1970) 308-316.

9 Fishman, R.A., Cerebrospinal Fluid in Diseases of the Nervous System, W.B. Saunders, Philadelphia, 1980, pp. 10-11.

10 Gillon, K.R.W. and Hawthorn, J.N., Transport of myo-inositol into endoneurial preparation of sciatic nerve from normal and streptozotocin-diabetic rats, Biochem. J., 210 (1983) 775-781.

11 Godfrey, D.A., Hallcher, L.M., Laird, M.H., Matschinsky, F.M. and Sherman, W.R., Distribution of myo-inositol in the cat cochlear nucleus, J. Neurochem., 38 (1982) 939-947.

12 Greene, D.A., De Jesus, P.V. and Winegrad, A.I., Effects of insulin and dietary myoinositol on impaired peripheral motor nerve conduction velocity in acute streptozotocin diabetes, $J$. Clin. Invest., 55 (1975) 1326-1336.

13 Greene, D.A. and Lattimer, S.A., Sodium and energy-dependent uptake of myo-inositol by rabbit peripheral nerve: competitive inhibition by glucose and lack of an insulin effect, $J$. Clin. Invest., 70 (1982) 1009-1018.

14 Greene, D.A. and Lattimer, S.A., Impaired rat sciatic nerve sodium-potassium adenosine triphosphate in acute streptozotocin diabetes and its correction by dietary myo-inositol supplementation, J. Clin. Invest., 72 (1983) 1058-1063.

15 Hammerman, M.R., Sacktor, B. and Daughaday, W.H., Myo- inositol transport in renal brush border vesicles and its inhibition by D-glucose, Am. J. Physiol, 239 (1980) F113-120.

16 Kletzien, R.F., Pariza, M.W., Becker, J.E. and Potter, V.R., A method using 3-O-D-glucose and phloretin for the determination of intracellular water space of cells in monolayer cultures, Anal. Biochem., 68 (1975) 537-544.

17 MacGregor, L.C. and Matschinsky, F.M., An enzymatic fluorimetric assay for myo-inositol, Anal. Biochem., 141 (1984) 382-389.

18 MacGregor, L.C., Rosecan, L.R., Laties, A.M. and Matschinsky, F.M., Altered retinal metabolism in diabetes. I. Microanalysis of lipid glucose, sorbitol and myo-inositol in the choroid and in the individual layers of the rabbit retina, J. Biol. Chem., 261 (1986) 4046-4051.

19 Nishizuka, Y., Turnover of inositol phospholipids and signal transduction, Science, 225 (1984) 1365-1370.

20 Segal, S., Hwang, S.M., Stern, J. and Pleasure, D., Inositol uptake by cultured isolated rat Schwann cells, Biochem. Biophys. Res. Commun., 120 (1984) 486-492.

21 Sherman, W.R., Hipps, P.P., Mauck, L.A. and Rasheed, A., Studies on enzymes of inositol metabolism. In W.W. Wells and F. Eisenberg Jr. (Eds.), Cyclitols and Phosphoinositides, Academic Press, New York, 1978, pp. 279-295.

22 Spector, R., Inositol accumulation by brain slices in vitro, $J$. Neurochem., 27 (1976) 1273-1276.

23 Spector, R. and Lorenzo, A.V., Myo-inositol transport in the central nervous system, Am. J. Physiol., 228 (1975) 1510-1518.

24 Spector, R. and Lorenzo, A.V., The origin of myo-inositol in brain, cerebrospinal fluid and choroid plexus, J. Neurochem., 25 (1975) 353-354.

25 Stein, O. and Stein, Y., Bovine aortic endothelial cells display macrophage-like properties toward acetylated [I-125]-labeled low density lipoprotein, Biochim. Biophys. Acta, 620 (1980) 631-635

26 Voyta, J.L., Netland, P.A., Via, D.P. and Zetterl, B.R., Specific labelling of endothelial cells using fluorescent acetylated-low density lipoprotein, J. Cell Biol., 99 (1984) 81A

27 Wallenstein, S., Zucker, C.L. and Fleiss, J.L., Some statistical methods useful in circulation research, Circ. Res., 47 (1980) 1-9.

28 Whiting, P.H., Palmano, K.P. and Hawthorne, J.N., Enzymes of myo-inositol and inositol lipid metabolism in rats with streptozotocin-induced diabetes, Biochem. J., 179 (1979) 549-553.

29 Yorek, M.A., Dunlap, J.A. and Ginsberg, B.H., Myoinositol uptake by four cultured mammalian cell lines, Arch. Biochem. Biophys., 246 (1986) 801-807.

30 Yorek, M.A., Dunlap, J.A. and Ginsberg, B.H., Myo-inositol metabolism in $41 \mathrm{~A} 3$ neuroblastoma cells: effects of high glucose and sorbitol levels, J. Neurochem., 48 (1987) 53-61. 